\section{Electrohydraulic lithotripsy of the common bile duct stone under transnasal direct cholangioscopy}

Electrohydraulic lithotripsy (EHL) has been recognized as a useful technique for the removal of choledocholithiasis, which is usually performed under the control of a peroral "mother-baby" cholangioscopic system or percutaneous transhepatic choledochoscopy [1,2]. However, the method may be disadvantageous due to its complicated procedure. Recently, the use of an ultraslim endoscope to direct cholangioscopy [3] as well as endoscopic retrograde cholangiopancreatography $[4,5]$ has been reported. Here, we report on a novel technique of EHL under the control of direct cholangioscopy using an ultrathin scope.

A 78-year-old woman visited our hospital complaining of epigastric colic pain. She had jaundice with elevated serum levels of bilirubin $(5.9 \mathrm{mg} / \mathrm{dL})$, alkaline phos-
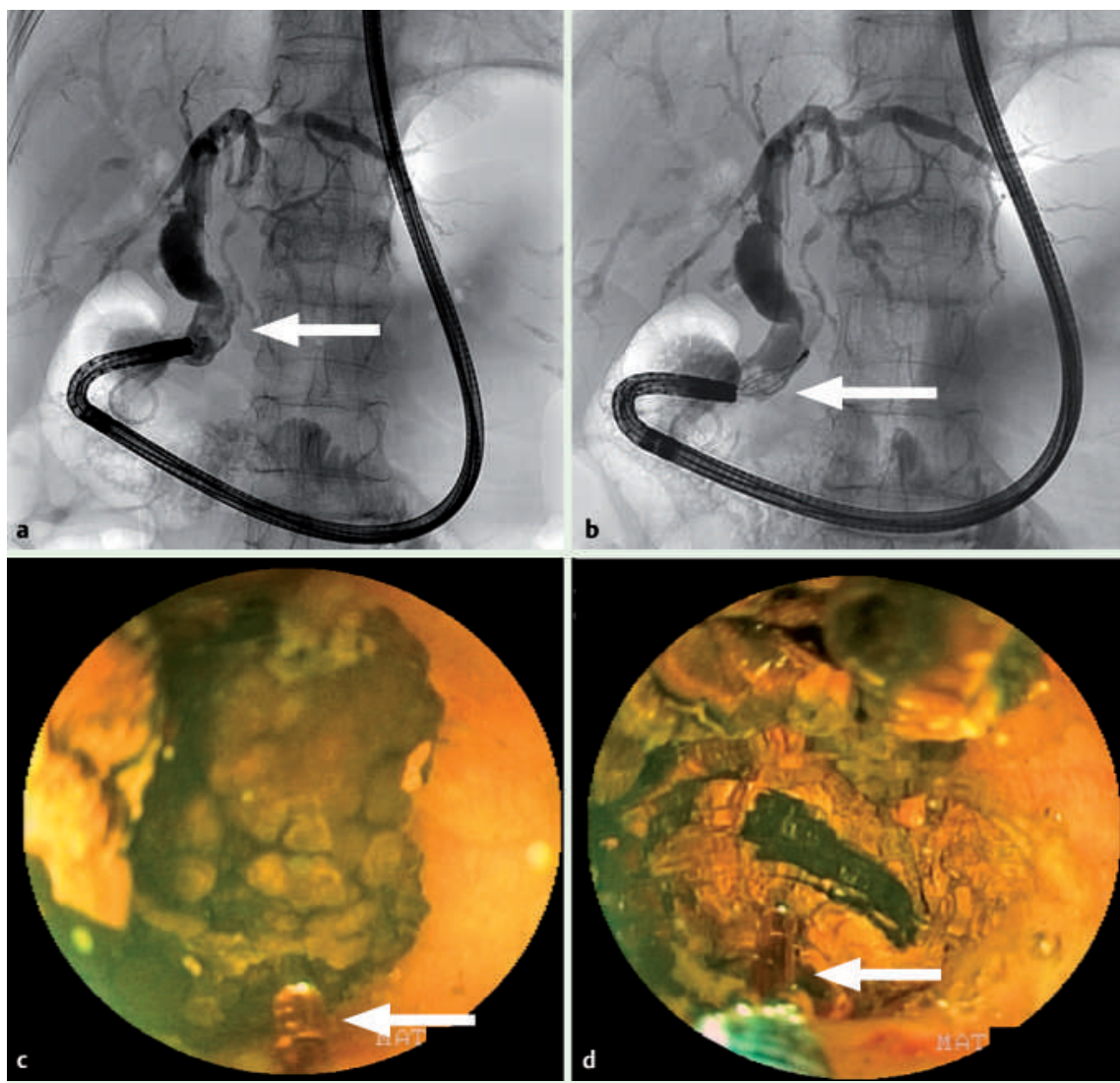

Fig. 1 Electrohydraulic lithotripsy (EHL) of a common bile duct (CBD) stone under transnasal direct cholangioscopy using an ultrathin scope. a Fluoroscopy of an ultrathin scope inserted in the CBD. An arrow indicates the CBD stone. $\mathbf{b}$ Fragmented stones were removed using a basket catheter after EHL (arrow). $\mathbf{c}$ and $\mathbf{d}$ Cholangioscopic view of the CBD stone before and after EHL, respectively. An arrow represents a bipolar electrode placed at the surface of the stone. cholangioscopy. Peroral EHL is often time-consuming and may sometimes cause dysphagia, probably due to the long-term compression of the pharynx by the scope. Transnasal EHL might be beneficial because the insertion route is likely to be less irritant than the transoral approach. Moreover, because the procedure does not require special equipment or invasive approaches, this new method can be applied widely to patients with CBD stones.

\section{Endoscopy_UCTN_Code_TTT_1AR_2AH}

A.Mori, K.Sakai, N.Ohashi, T.Maruyama, H.Tatebe, T.Shibuya, H.Inoue, M.Okuno Department of Gastroenterology, Inuyama Chuo Hospital, Aichi, Japan

\section{References}

1 Bonnel DH, Liguory CE, Cornud FE, Lefebvre JF. Common bile duct and intrahepatic stones: results of transhepatic electrohydraulic lithotripsy in 50 patients. Radiology 1991; 180: $345-348$

2 Arya N, Nelles SE, Haber GB et al. Electrohydraulic lithotripsy in 111 patients: a safe and effective therapy for difficult bile stones. Am J Gastroenterol 2004; 99: $2330-2334$

3 Larghi A, Waxman I. Endoscopic direct cholangioscopy by using an ultra-slim upper endoscope: a feasibility study. Gastrointest Endosc 2006; 63: 853-857

4 Mori A, Asano T, Maruyama Tet al. Transnasal ERCP/ENBD using an ultrathin esophagogastroduodenoscope. J Gastroenterol 2006; 41: $1237-1238$

5 Mori A, Ohashi N, Maruyama T et al. Endoscopic retrograde cholangiopancreatography through gastric stoma using ultrathin endoscope: a novel approach. Endoscopy 2008; 40

\section{Bibliography}

Dol $10.1055 / \mathrm{s}-2007-995446$

Endoscopy 2007; 39: E63-E63

(c) Georg Thieme Verlag KG Stuttgart · New York . ISSN 0013-726X

\section{Corresponding author}

\section{A. Mori, MD}

Department of Gastroenterology

Inuyama Chuo Hospital

Aichi 484-8511

Japan

Fax: +81-568-628761

a-mori@inuyamachuohospital.or.jp 